\title{
Assessing Preliminary Impact of the North Carolina Community Transformation Grant Project Farmers' Market Initiatives Among Rural Residents
}

\author{
Stephanie B. Jilcott Pitts, $\mathrm{PhD}^{1}$; Jared T. McGuirt, $\mathrm{MPH}^{2}$; Qiang Wu, $\mathrm{PhD}^{3}$; \\ Jill Rushing, $\mathrm{MS}^{4}$; Daniella Uslan, $\mathrm{MPH}^{5}$; Karen K. Stanley, RDN, LDN ${ }^{6}$; \\ Sally L. Bullock, $\mathrm{MPH}^{2}$; Rachel K. Ward, $\mathrm{MPH}, \mathrm{DrPH}^{7}$; Ann P. Rafferty, $\mathrm{PhD}^{8}$; \\ Alice S. Ammerman, DrPH ${ }^{9}$
}

\begin{abstract}
Objective: Using the Social Determinants of Health as the study's theoretical underpinning, the authors examined the impact of the North Carolina Community Transformation Grant Project farmers' market initiatives on changes in awareness and use of farmers' markets, and fruit and vegetable consumption.

Methods: During the farmers' market season, the researchers conducted a random digit-dial telephone survey among residents in 3 rural North Carolina counties to examine changes in farmers' market awareness, shopping, and fruit and vegetable consumption. They examined change over 1 year using $t$ tests, chi-square tests, and propensity score matching.

Results: In 1 county there were increases in farmers' market shopping and fruit and vegetable consumption, and in 1 county there were decreases in farmers' market shopping and fruit and vegetable consumption. Conclusions and Implications: The impact of farmers' market initiatives may be affected by countyspecific socioeconomic contexts.
\end{abstract}

Key Words: nutrition, health promotion, social determinants of health, farmers' markets (J Nutr Educ Behav. 2016;48:343-349.)

Accepted March 4, 2016.

Department of Public Health, Brody School of Medicine, East Carolina University, Greenville, NC

Department of Nutrition, University of North Carolina at Chapel Hill, Chapel Hill, NC

Department of Biostatistics, East Carolina University, Greenville, NC

North Carolina Department of Health and Human Services, Raleigh, NC

SNAP-Ed, Center for Health Promotion and Disease Prevention (a CDC Prevention Research Center), University of North Carolina at Chapel Hill, Chapel Hill, NC

Chronic Disease and Injury Section, Division of Public Health, North Carolina Department of Health and Human Services, Raleigh, NC

Department of Community Health, East Tennessee State University, Johnson City, TN

Department of Public Health, East Carolina University, Greenville, NC

Department of Nutrition, Gillings School of Global Public Health, Center for Health Promotion and Disease Prevention, University of North Carolina at Chapel Hill, Chapel Hill, NC Conflict of Interest Disclosure: The authors' conflict of interest disclosures can be found online with this article on www.jneb.org.

Address for correspondence: Stephanie B. Jilcott Pitts, PhD, Department of Public Health, Brody School of Medicine, East Carolina University, 600 Moye Blvd, MS 660, Lakeside Annex 7, Greenville, NC, 27834; Phone: (252) 744-5572; Fax: (252) 744-4008; E-mail: jilcotts@ecu.edu

\section{INTRODUCTION}

Obesity and nutrition-related chronic diseases continue to affect underserved US residents disproportionately. ${ }^{1,2}$ These disparities are partially the result of inequities in the food environment; underserved areas often have less access to healthy food sources such as supermarkets and farmers' markets compared with more advantaged areas. ${ }^{3,4}$ Social Determinants of Health theory suggests that research on the underlying systems that result in health disparities must be examined and addressed. $^{5,6}$ In a qualitative study based in the southern US and framed by the Social Determinants of Health, a determinant of health at the environmental level included lack of access to healthy foods. ${ }^{6}$ Researchers suggested obesity prevention strategies such as increasing access to farmers' markets and supermarkets in underserved areas, ${ }^{7,8}$ because various studies have found that shopping at farmers' markets 
is associated with increased fruit and vegetable consumption. $^{9-13}$ Interventions to increase access to farmers' markets have taken place as a result of the Communities Putting Prevention to Work $^{14}$ and Community Transformation Grant $^{15}$ projects. For example, North Carolinaimplemented a farmers' market initiative as a part of the North Carolina Community Transformation Grant (CTG) Project, in which farmers' markets were created and/or enhanced through additional promotion, advertising, structures, nutrition education, and enhanced financial access through adding Supplemental Nutrition Assistance Program (SNAP)/ Electronic Benefit Transfer (EBT).

Ten North Carolina CTG Project regions, encompassing 98 of the state's 100 counties, collaborated with local partners to create new farmers' markets and enhance existing ones. Enhancements included increasing transportation options to the market, improving the structure of the market, implementing SNAP/EBT at the market, and creating land use protection in support of farmers' markets. The North Carolina CTG Project also supported markets in their promotional efforts and activities related to nutritional education, and an North Carolina CTG Project communications specialist worked with local communication staff members to promote farmers' markets. Enhancements were thought to lead to greater awareness and subsequent use of farmers' markets, which would lead to greater fruit and vegetable consumption and more optimal health.

Because North Carolina includes approximately $90 \%$ rural residents, ${ }^{16}$ the researchers had the unique opportunity to evaluate the effectiveness of the North Carolina CTG Project farmers' market initiative in rural areas, whose population is particularly burdened by diet-related disease compared with that in urban areas. ${ }^{1,2}$ Thus, this study's findings can inform future policy and environmental change efforts in rural areas. Evaluation of policy and environmental change efforts in rural areas is potentially more difficult than in urban areas, because existing population-based data sources, such as Behavioral Risk Factor Surveillance System (BRFSS) data, are not available for many rural counties because of small sample sizes. Therefore, the purpose of this article was to examine the impact of North Carolina CTG Project farmers' market initiatives on awareness and use of farmers' markets, and changes in fruit and vegetable consumption among a cross-sectional sample of random digit-dial telephone survey participants in 3 rural North Carolina counties. Change in farmers' market awareness and use, and fruit and vegetable consumption were assessed, comparing 2013 and 2014.

\section{METHODS}

\section{Study Setting and Participants}

Through the CTG Program, the Centers for Disease Control and Prevention (CDC) provided support to awardees across the US in the following intervention areas: tobacco-free living, active living and healthy eating, and clinical and community preventive services to prevent and control high blood pressure and high cholesterol. This article describes 1 component of the North Carolina CTG Project's healthy eating intervention, increasing the number of new and/or enhanced farmers' markets. Farmers' markets included roadside stands and produce markets, and were defined according to the number of farmers operating each venue. Farmers' markets were defined as outlets with multiple farmer vendors with predicable locations and hours of operation; roadside stands were defined as a single farmer vendor, and produce stands were non-farmer outlets, such as those operated by a produce distributor.

This study examined farmers' market shopping and fruit and vegetable consumption among a randomly selected sample of county residents in each of 3 rural counties in North Carolina: county A (Mountain Region, Western North Carolina; $\mathrm{n}=108$ in 2013 and $n=100$ in 2014), county $B$ (Coastal Plains, Eastern North Carolina; $\mathrm{n}=100$ in 2013 and 2014), and county C (Piedmont, Central North Carolina, $\mathrm{n}=99$ in 2013 and $\mathrm{n}=100$ in 2014). The counties were selected based on being representative of the region and on geographic spread throughout North Carolina CTG regions, with each region and county using various farmers' market promotional strategies and initiatives. Each county was classified as non-metro by the Office of Management and Budget. ${ }^{17}$ County $\mathrm{A}$ was located in CTG region 3, which included 3 new and 14 enhanced farmers' markets. County B was in CTG region 9, which included 9 new markets and 14 enhanced markets. County C was in CTG region 6, which included 9 new markets and 2 enhanced markets. Individuals within counties were selected using a random digit-dial telephone survey methodology in June through September, 2013, and a separate sample was contacted 1 year later, in May through June, 2014. In each county, there was slight overlap in those called: $5 \%$ of the sample for county A participated in the survey in both years; $3 \%$ for county B; and $1 \%$ for county $C$. The sample was purchased from Survey Sampling, Inc (Encino, CA), and included cellular and landlines, as in a previous study. ${ }^{9}$ This study was reviewed and approved by the East Carolina University Institutional Review Board.

\section{Farmers' Market Awareness, Use, and Fruit and Vegetable Consumption}

The researchers assessed awareness of farmers' markets by providing a list of markets in the county and asking whether participants had heard of it before and whether they knew how to find the market. Affirmative responses were summed to create an awareness score. ${ }^{11}$ For example, if a respondent had heard of a market and knew how to find it, that represented 2 points. Total awareness scores were based on the number of markets in each county. In county A, there were 2 markets in 2012 and 3 in 2014. In county B, there were 3 markets in 2012 and 3 in 2014. In county C, in 2012 there were 10 markets and 14 markets in 2014. Thus, the maximum awareness score in county $\mathrm{C}$ was higher than in counties $\mathrm{A}$ and $B$ because there were more markets in county $C$ vs counties $A$ and $B$. The survey item assessing farmers' market awareness changed slightly from 2013 to 2014 to include any additional markets in each county.

Farmers' market use (ie, shopping) was assessed by asking a question that was included on the 2013 North Carolina BRFSS: How often in the past 12 months did you buy fruits or vegetables that were locally grown from a farmers' market, community supported agriculture (CSA), roadside 
stand, or pick-your-own produce farm? Response categories ranged from $\geq 2$ times per week to never, and for the analysis responses were dichotomized into never vs ever purchasing owing to distribution of the data. In 2014, participants were also asked, In the past 12 months, has your frequency of shopping at farmers' markets decreased, stayed the same, or increased?

Barriers and facilitators to farmers' market shopping were also assessed (yes/no) using a list generated from examining barriers and facilitators as assessed in prior studies ${ }^{11,13}$; respondents were asked to mark only 1 main barrier and 1 main facilitator. Barriers on the list included: no SNAP, EBT access, no credit/debit accepted, not enough money to shop, I don't have transportation to the market, prices are too high, extreme weather, not enough parking, market days and hours aren't convenient, out of the way, I get what I need from other places, I don't know where any markets are, and other (specify). Facilitators on the list included: support local farmers, fresher produce, produce tastes better, better prices, it is close to home, it is close to work, produce is grown with fewer pesticides, good service, quality of the products, variety of the products, consistency of the products, convenient location, friendly atmosphere, and other (specify).

Participants were also asked how likely they would be to shop at a farmers' market given various scenarios, including more public transportation to the market, more nutrition education at the market, more advertising, more parking, more vendors at the market, more shelter from the weather, more accessible facilities for individuals with disabilities, and increased availability of SNAP/EBT. Response options were on a 5-point Likert scale ranging from much less likely to much more likely.

Fruit and vegetable consumption was assessed in 2 ways: (1) using the Block Fruit, Vegetable, and Fiber Screener questions (Block FV), 18,19 and (2) the BRFSS questions. The Block FV asks respondents about how often they typically eat various fruits and vegetables, ranging from less than once per week to $\geq 2$ times per day. Food items include fruit juice, fruit, vegetable juice, green salad, potatoes, vegetable soup, and other vegetables. The Block FV has been used in a prior study to examine intervention-related change in fruit and vegetable consumption. ${ }^{20}$ The BRFSS questions ask respondents about fruit and vegetable consumption over the past 30 days and respondents can indicate frequency of consumption by day, week, or month. Food items include fruit (not juice), green vegetables, orange vegetables, and other vegetables. The following question was also asked: Do you purchase more fruits and vegetables for your household when you are able to shop at a farmers' market/produce stand (in addition to a supermarket or other food stores), compared with when you shop at a supermarket only? Response options were: yes, no, and don't know. The researchers also asked: Compared with other places you have purchased food, do you think a farmers' market is more or less expensive? Response options included: more expensive, less expensive, and the same price.

\section{Statistical Analysis}

Descriptive statistics for all variables of interest were examined, including general trends in changes in farmers' market awareness, use, and fruit and vegetable consumption over 1 year by county, using $t$ tests to compare means between years and chi-square tests to compare proportions between years. Analyses were completed in each county separately owing to countyand region-specific farmers' market initiatives present in each county. To minimize the problem of different samples in each county each year, the authors used propensity score matching. ${ }^{21}$ A logistic regression model was fit with year (2013/2014) as the dependent variable, and age, sex, race, college education (yes/no), marital status (married/with partner vs single/separated/divorced/widowed), and number of children $(0 />0)$ as the independent variables, to estimate the propensity score. Then $1 /$ propensity score was used for the actual year of the data to weight all subsequent analyses. $P<.05$ was considered statistically significant and all analyses were conducted with SAS, version 9.3 software (SAS Institute, Cary, NC, 2011/2012).

\section{RESULTS}

\section{Participant Characteristics}

Table 1 shows the weighted characteristics of respondents in 2013 vs 2014. Overall, mean age across counties was age $55-58$ years, mean body mass index was $27-30 \mathrm{~kg} / \mathrm{m}^{2}$, and a small percentage was enrolled in the Special Supplemental Nutrition Assistance Program for Women, Infants, and Children and SNAP. A greater proportion of county B residents were enrolled in the Special SNAP for Women, Infants, and Children and SNAP, compared with county A and $\mathrm{C}$ residents.

\section{Farmers' Market Awareness, Use, and Fruit and Vegetable Consumption}

Table 2 shows awareness and use of farmers' markets, and both measures of fruit and vegetable consumption in each county in each year, weighted by the propensity score. Farmers' market awareness did not change appreciably from 2013 to 2014 in any of the counties. There was a statistically significant increase in farmers' market use in 2014 vs 2013 in county A (chisquare $=5.6 ; P=.02$ ). In counties $\mathrm{B}$ and $C$, there were no statistically significant changes in farmers' market use from 2013 to 2014 . In county A, there was a statistically significant increase in fruit and vegetable consumption between 2013 and 2014 for both the Block FV and BRFSS estimates $(t$ for Block FV $=-2.5, P=.01 ; t$ for BRFSS $=-2.2, P=.03$ ), no statistically significant change in fruit and vegetable consumption in county $\mathrm{B}$, and a statistically significant decrease in fruit and vegetable consumption in county $\mathrm{C}$ ( $t$ value for Block $\mathrm{FV}=2.8$, $P=.01 ; t$ for BRFSS $=2.5, P=.01$ ).

There were no significant changes in people who responded affirmatively that they purchased more fruits and vegetables when they were able to shop at a farmers' market in any of the counties. Notably, when asked about the relative expense of farmers' markets, the percentage stating that farmers' markets were more expensive was significantly higher in 2014 vs 2013 in counties B and C.

When asked about whether the frequency of shopping at farmers' markets 
Table 1. Weighted Characteristics of North Carolina Farmers' Market Evaluation Participants in a 3-County Random Digit-Dial Survey Administered in 2013 and 2014, by County

\section{Characteristic}

Year

Age, y (mean $[S D])$

Body mass index $\left(\mathrm{kg} / \mathrm{m}^{2}\right)$ (mean [SD])

Gender (\% male)

Race (\% black/African American)

Ethnicity (\% Hispanic)

Education (\% with less than college degree)

Currently receive WIC? (n, \% yes)

Redeemed WIC FMNP vouchers, $n^{b}$

Currently receive SNAP? ( $\mathrm{n}, \%$ yes)

Used SNAP/EBT at farmers' market, $n$

Participated in senior FMNP, $n^{a}$

\section{County A}

2013

$(n=108)^{2}$

2014

( $\mathrm{n}=100)$

2013

County B

$55.3(15.8)$

$27.5(4.9)$

55.3 (15.2)

$(\mathrm{n}=100)$

2014

( $\mathrm{n}=100)$

County C

38.

$38.2 \quad 38$.

$1.0 \quad 1.0$

1.0

0.0

44.3

1.0

44.9

$1,0.8$

$5,5.7$

1

19, 16.6

1

1

9, 11.0

$\begin{array}{rrr}3 & 0 & 13 \\ 3 & 3 & 3\end{array}$

$\begin{array}{rrr}3 & 0 & 13 \\ 3 & 3 & 3\end{array}$

EBT indicates Electronic Benefit Transfer; FMNP = Farmers' Market Nutrition Program; SNAP = Supplemental Nutrition Assistance Program; WIC = Special Supplemental Nutrition Assistance Program for Women, Infants, and Children.

${ }^{a} \mathrm{n}=$ unweighted sample size; ' $\mathrm{b}$ uestions about WIC FMNP vouchers and SNAP/EBT use at farmers' markets were asked only of those respondents who reported receiving WIC or SNAP, respectively. This resulted in small numbers, and so only the number (and not weighted percentage) is presented.

decreased, stayed the same, or increased compared with previous shopping frequency (asked only in 2014), 17.7\% of county A respondents, $15.2 \%$ of county B respondents, and $16.0 \%$ of county $\mathrm{C}$ respondents stated that shopping increased.

In all counties, the top barriers and facilitators remained largely unchanged from 2013 to 2014. People stated that barriers included: "Market days and hours are not convenient," "The market is out of the way," and "I get what I need from other places."
Facilitators included fresher produce, support of local farmers, and quality of the products (Table 3) (data presented are unweighted because results between weighted and unweighted data were similar).

Table 4 shows various scenarios and (unweighted) percentages of respondents indicating that they would be much more likely to shop at a farmers' market given a particular scenario. In county A in 2013, the top scenarios were more parking at the market and more transportation to the market, in contrast to 2014, in which more vendors and more shelter from the weather were more frequently selected as scenarios that would make respondents more likely to visit a farmers' market. In county B in 2013, the top strategies were more accessible facilities for people with disabilities and more transportation to the market, whereas in 2014, the top strategies were more vendors and more shelter from the weather. In county $C$, the scenario with more vendors was a top strategy in both years.

Table 2. Differences Between Weighted Farmers' Market Awareness, Use, and Fruit and Vegetable Consumption in 2013-2014

\begin{tabular}{|c|c|c|c|c|c|c|c|c|c|}
\hline \multirow[b]{2}{*}{ Characteristic } & \multicolumn{2}{|l|}{ County A } & \multicolumn{3}{|c|}{ County B } & \multicolumn{3}{|c|}{ County C } & \multirow[b]{2}{*}{$\boldsymbol{P}$} \\
\hline & 2013 & 2014 & $\boldsymbol{P}$ & 2013 & 2014 & $\boldsymbol{P}$ & 2013 & 2014 & \\
\hline Farmers' market awareness (mean [SD]) & $2.3(2.3)$ & $2.5(2.4)$ & .49 & $0.9(1.4)$ & $1.1(1.5)$ & .34 & $6.8(7.4)$ & $6.2(6.6)$ & .56 \\
\hline Farmers' market use (\% ever) & 54.5 & 69.9 & .02 & 42.3 & 43.9 & .80 & 56.1 & 54.2 & .84 \\
\hline $\begin{array}{l}\text { Block Fruit and Vegetable Consumption } \\
\text { (mean [SD]) }\end{array}$ & $3.6(1.8)$ & $4.3(1.9)$ & .01 & $3.6(1.9)$ & $3.9(2.1)$ & .29 & $4.3(1.7)$ & $3.6(1.9)$ & .01 \\
\hline $\begin{array}{l}\text { Behavioral Risk Factor Surveillance System Fruit } \\
\text { and Vegetable Consumption (mean [SD]) }\end{array}$ & $2.7(1.6)$ & $3.3(2.2)$ & .03 & $2.9(2.6)$ & $2.9(2.1)$ & .94 & $3.3(2.3)$ & $2.6(1.6)$ & .01 \\
\hline $\begin{array}{l}\text { Purchase more fruits and vegetables when able } \\
\text { to shop at farmers' market (\% yes) }\end{array}$ & 39.1 & 48.7 & .90 & 28.1 & 30.1 & .77 & 44.7 & 34.3 & .10 \\
\hline Farmers' markets are more expensive (\% yes) & 26.4 & 34.6 & .09 & 31.9 & 37.8 & $<.001$ & 16.4 & 22.7 & .05 \\
\hline
\end{tabular}

Note: $t$ tests were used to compare county weighted means; chi-square tests were used to compare county weighted frequencies. Statistical significance was set at $P=.05$. 
County A

2013

Market days and hours aren't convenient

Out of the way

I get what I

need from

other places

Other

Facilitators

Fresher produce
Support local
farmers
Quality of
products

2014

Market days and Out of the way

hours aren't

convenient

Out of the way

Market days and

hours aren't

convenient

I get what I
need from
other places

I don't have

transportation

to the market

I don't where

any markets are

Other

Fresher produce

Support local farmers

Quality of

products

Fresher produce

Produce tastes

better

Support local

farmers
County B

2014

Out of the way

hours aren't

convenient

Fresher produce

Quality of

products

Better prices
County C

2013

2014

Market days and Market days and hours aren't hours aren't convenient convenient

Out of the way

Market days and Out of the way Other

$\begin{array}{cc}\text { I don't know } & \text { I get what I } \\ \text { where any } & \text { need from } \\ \text { markets are } & \text { other places } \\ \text { Other } & \end{array}$

| get what | need from

\section{other places}

Fresher produce

Fresher produce

Support local farmers

Produce tastes better

Support local farmers

Quality of products

Produce tastes better

Note: When more than 1 barrier or facilitator is in the cell, this indicates a tie.

\section{DISCUSSION}

The goal of the North Carolina CTG Project farmers' market initiatives was to increase awareness of farmers' markets, subsequently leading to increased farmers' market use, and that these increases would lead to increased produce consumption among residents. However, in this initial impact evaluation,
Table 4. Percentage (Unweighted) of Respondents Who Would Be Much More Likely to Shop at a Farmers' Market Given Each Scenario ${ }^{a}$

\begin{tabular}{|c|c|c|c|c|c|c|}
\hline \multirow[b]{2}{*}{ List of Scenarios } & \multicolumn{2}{|c|}{ County A (\%) } & \multicolumn{2}{|c|}{ County B (\%) } & \multicolumn{2}{|c|}{ County C (\%) } \\
\hline & 2013 & 2014 & 2013 & 2014 & 2013 & 2014 \\
\hline $\begin{array}{l}\text { Public transportation } \\
\text { to market }\end{array}$ & 9.5 & 6.0 & 14.0 & 9.1 & 4.0 & 3.0 \\
\hline $\begin{array}{l}\text { More nutrition education } \\
\text { activities at market }\end{array}$ & 3.8 & 5.0 & 3.0 & 11.1 & 4.0 & 1.0 \\
\hline More advertising of market & 4.8 & 7.0 & 6.0 & 11.1 & 3.0 & 5.0 \\
\hline $\begin{array}{l}\text { More promotional events } \\
\text { held at market }\end{array}$ & 6.7 & 8.1 & 7.0 & 10.1 & 3.0 & 8.0 \\
\hline More parking at market & 10.5 & 6.0 & 4.0 & 13.1 & 4.0 & 2.1 \\
\hline More vendors at market & 7.6 & 11.0 & 7.0 & 18.2 & 5.1 & 14.1 \\
\hline More shelter from weather & 7.6 & 11.2 & 8.0 & 16.5 & 1.0 & 6.1 \\
\hline $\begin{array}{l}\text { More accessible facilities } \\
\text { for people with disabilities }\end{array}$ & 7.6 & 5.1 & 15.0 & 10.1 & 3.1 & 4.0 \\
\hline $\begin{array}{l}\text { Supplemental Nutrition } \\
\text { Assistance Program } \\
\text { Electronic Benefit } \\
\text { Transfer access }\end{array}$ & 6.7 & 4.0 & 10.0 & 8.1 & 2.0 & 2.0 \\
\hline
\end{tabular}

aUsing the following scale $(1=$ much less and $5=$ much more likely), please rate how likely you would be to shop at a farmers' market if there were .... there was no change in farmers' market awareness in the 3 counties between 2013 and 2014. There was a slight increase in farmers' market use and in fruit and vegetable consumption in county $A$ and no change in use in counties B and C. Results in county A support those of research by Evans et al, who found that adding farm stands in low-income areas resulted in increases in fruit and vegetable consumption among residents. ${ }^{13}$ In county A, it could be that residents were already aware of farmers' markets but became more motivated to use farmers' markets in the county owing to heightened promotions and advertisements.

It is interesting that county $C$ residents decreased fruit and vegetable consumption even though county C has more farmers' markets than do counties A and B. Because county C had more markets and a greater increase in markets from 2012 to 2014 (10 markets in 2012 and 14 in 2014) than did counties A (2 markets in 2012 and 3 in 2014) and B (3 markets in 2012 and 3 in 2014), it could be that the best strategy is to promote the markets that a county has, compared with establishing more farmers' markets. This may be 
especially true in rural areas, where the customer base might not be able to support additional markets. In addition, the top barriers to shopping at farmers' markets were stated as: "market days and hours not convenient," "out of the way," and "I get what I need from other places." The top facilitator for county $\mathrm{C}$ residents to shop more at farmers' markets was "more vendors," which possibly indicated that county $C$ had many farmers' markets, but possibly not enough vendors at each location to attract regular customers. Taken together, results suggest that increasing market hours and variety is possibly more important than establishing new markets to promote farmers' market shopping and increased fruit and vegetable consumption in rural areas. Because of this study's findings about perceived prices of produce at farmers' markets, it may also be necessary to present marketing materials to show potential consumers that produce at farmers' markets is the same price as or lower than produce at supermarkets. ${ }^{22}$ The current results are in agreement with the general findings of Fang et al, ${ }^{23}$ who conducted interviews with farmers' market stakeholders in Pennsylvania and emphasized the notion that simply establishing a new farmers' market in an underserved community may not be a silver bullet: Thoughtful consideration of how to address and overcome barriers to establishing and maintaining farmers' markets are required to promote market vitality and optimal community health.

This study has limitations, including the potential for confounding by unmeasured factors in the different groups sampled at each time point. To minimize this limitation, the researchers used propensity score matching. Despite the use of propensity scores, it would be overstating the results to say that any increases in fruit and vegetable consumption observed were the solely the result of North Carolina CTG farmers' market initiatives. In addition, increases in fruit and vegetable consumption, without subsequent decreases in energy intake from other more calorie-dense food sources, will not result in population-level shifts in obesity prevalence. It is difficult to evaluate such broad initiatives because individuals cannot be randomized into intervention and control groups. Therefore, the authors relied on data from a random digit-dial survey. This study was also limited in that exposure to farmers' market initiatives other than changes in awareness over 1 year could not be assessed. The 1-year follow-up may have been inadequate to measure change in awareness over time. A reliance on self-reported data on farmers' market awareness, use, and fruit and vegetable consumption is also a limitation, which may include recall bias and other errors. In addition, the authors used 2 measures of fruit and vegetable consumption, which yielded different results in some cases, indicating their varying degrees of error. Although the random digit-dial methodology included cellular phone numbers, the sample may not have included low-income individuals with pay-per-use phones.

\section{IMPLICATIONS FOR RESEARCH AND PRACTICE}

Because rural residents face a disproportionate burden of nutritionrelated chronic disease, it is important to learn about ongoing initiatives to promote healthy eating among this population. Next steps will include more in-depth evaluation to determine the most effective ways to advertise and enhance farmers' markets to increase salience to underserved, rural residents. Results of the current study suggest a new hypothesis to test: There may be a level of market saturation in rural areas at which adding new markets only diffuses the customer base and reduces the variety of products offered at markets. Future research could examine this question in a variety of rural settings to determine threshold levels for numbers of markets, vendors, and customer base needed to promote thriving farmers' markets and healthy communities.

\section{ACKNOWLEDGMENTS}

This article was supported in part by a contract with the CDC (FOA CDCRFA-DP11-1115PPHF11). Portions of this project's work involve the Communities Transforming initiative supported by CDC funding. However, the findings and conclusions in this article are those of the authors and do not necessarily represent the official position of the CDC. Users of this document should be aware that every funding source has different requirements governing the appropriate use of those funds. Under US law, no Federal funds are permitted to be used for lobbying or to influence, directly or indirectly, specific pieces of pending or proposed legislation at the federal, state, or local levels. Organizations should consult appropriate legal counsel to ensure compliance with all rules, regulations, and restriction of any funding sources.

\section{REFERENCES}

1. Befort CA, Nazir N, Perri MG. Prevalence of obesity among adults from rural and urban areas of the United States: findings from NHANES (2005 - 2008). J Rural Health. 2012;28:392-397.

2. Liu JH, Jones SJ, Sun H, Probst JC, Merchant AT, Cavicchia P. Diet, physical activity, and sedentary behaviors as risk factors for childhood obesity: an urban and rural comparison. Child Obes. 2012;8:440-448.

3. Liese AD, Weis KE, Pluto D, Smith E, Lawson A. Food store types, availability, and cost of foods in a rural environment. J Am Diet Assoc. 2007;107: 1916-1923.

4. Larson NI, Story MT, Nelson MC. Neighborhood environments: disparities in access to healthy foods in the U.S. Am J Prev Med. 2009;36:74-81.

5. Carey G, Crammond B. Systems change for the social determinants of health. BMC Public Health. 2015;15:662.

6. Scott AJ, Wilson RF. Social determinants of health among African Americans in a rural community in the Deep South: an ecological exploration. Rural Remote Health. 2011;11:1634.

7. Blanck HM, Thompson OM, Nebeling L, Yaroch AL. Improving fruit and vegetable consumption: use of farm-to-consumer venues among US adults. Prev Chronic Dis. 2011;8:A49.

8. Khan LK, Sobush K, Keener D, et al. Recommended community strategies and measurements to prevent obesity in the United States. MMWR Recomm Rep. 2009;58:1-26.

9. Jilcott Pitts SB, Gustafson A, Wu Q, et al. Farmers' market use is associated with fruit and vegetable consumption in diverse southern rural communities. Nutr J. 2014;13:1. 
10. Jilcott Pitts SB, Wu Q, McGuirt JT, Crawford TW, Keyserling TC, Ammerman AS. Associations between access to farmers' markets and supermarkets, shopping patterns, fruit and vegetable consumption and health indicators among women of reproductive age in eastern North Carolina, U.S.A. Public Health Nutr. 2013;16:1944-1952.

11. Jilcott Pitts SB, Wu Q, Demarest CL, et al. Farmers' market shopping and dietary behaviors among Supplemental Nutrition Assistance Program Participants. Public Health Nutr. 2015;18: 2407-2414.

12. Grin BM, Gayle TL, Saravia DC, Sanders LM. Use of farmers markets by mothers of WIC recipients, Miami-Dade County, Florida, 2011. Prev Chronic Dis. 2013;10:E95.

13. Evans AE, Jennings R, Smiley AW, et al. Introduction of farm stands in low-income communities increases fruit and vegetable among community residents. Health Place. 2012;18:1137-1143.

14. Bunnell R, O'Neil D, Soler R, et al. Fifty communities putting prevention to work: accelerating chronic disease prevention through policy, systems and environmental change. J Comm Health. 2012;37:1081-1090.

15. Centers for Disease Control and Prevention Investments in community health: Community Transformation Grant program. http://www.cdc.gov/nccdphp/dch /programs/communitytransformation /pdf/FINAL_CTG_StrategyReport-092 012v2_TAG508.pdf. Accessed March 22, 2016.

16. US Census Bureau. 2010 census of population. http://www.census.gov/geo/ www/ua/2010urbanruralclass.html. Accessed March 22, 2016.

17. US Census Bureau. Metropolitan and micropolitan statistical areas. http://www. census.gov/population/metro/. Accessed March 22, 2016.

18. Ritenbaugh P, Ritenbaugh C, Treiber F, et al. Evaluation of a brief telephone questionnaire to estimate fruit and vegetable consumption in diverse study populations. Epidemiology. 1993;4:455-463.

19. Block G, Gillespie C, Rosenbaum EH, et al. A rapid food screener to assess fat and fruit and vegetable intake. Am J Prev Med. 2000;8:284-288.

20. Keyserling TC, Sheridan SL, Draeger LB, et al. A comparison of live counseling with a web-based lifestyle and medication intervention to reduce coronary heart disease risk: a randomized clinical trial. JAMA Intern Med. 2014;174:1144-1157.

21. Rubin DB. Estimating causal effects from large data sets using propensity scores. Ann Intern Med. 1997;127(8 part 2):757-763.

22. McGuirt JT, Jilcott SB, Liu H, Ammerman AS. Produce price savings for consumers at farmers' markets compared to supermarkets in North Carolina. J Hunger Envir Nutr. 2011;6: 86-98.

23. Fang M, Buttenheim AM, Havassy J, Gollust S. "It's not an 'If you build it they will come' type of scenario": stakeholder perspectives on farmers' markets as a policy solution to food access in low-income neighborhoods. J Hunger Environ Nutr. 2013;8: 39-60. 
CONFLICT OF INTEREST

The authors have not stated any conflicts of interest. 